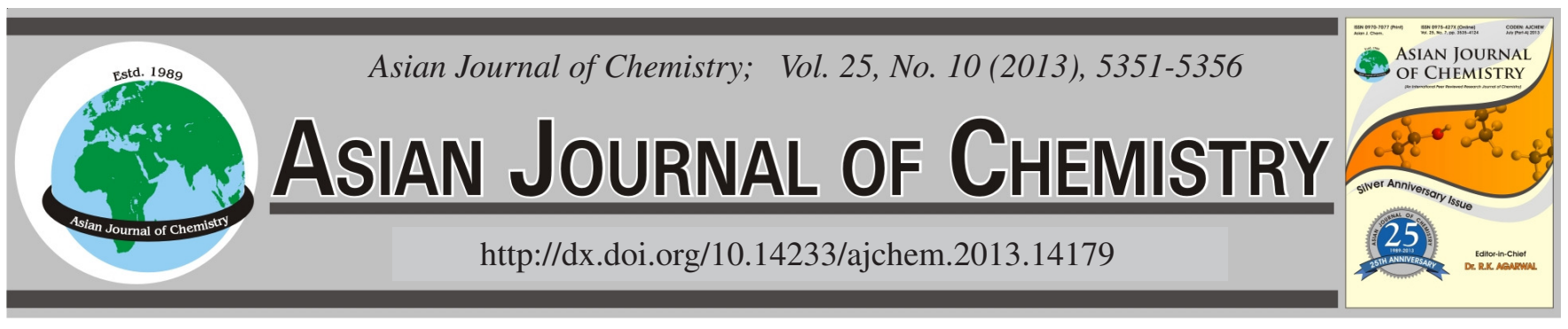

\title{
Sorptive Elimination of Alizarin Red-S Dye from Water Using Citrullus lanatus Peels in Environmentally Benign Way Along with Equilibrium Data Modeling
}

\author{
RABia REHMAN* and TARIQ MAHMUd
}

Institute of Chemistry, University of the Punjab, Lahore-54590, Pakistan

*Corresponding author: Fax: +92 42 99230998; Tel: +92 42 99230463; Ext: 870; E-mail: grinorganic@ yahoo.com

\begin{abstract}
Textile industry effluents comprised of various toxic and non biodegradable chemicals, especially non-adsorbed dyeing materials, having synthetic origin. Alizarin Red-S dye is one such examples. In this work, sorptive removal of Alizarin Red-S from water was investigated using Citrullus lanatus peels, in batch mode on laboratory scale. It was observed that adsorption of dye on Citrullus lanatus peels increases with increasing contact time and temperature, but decreases with increasing $\mathrm{pH}$. Isothermal modeling indicated that physiosorption occurred more as compared to chemi-sorption during adsorption of Alizarin Red-S by Citrullus lanatus peels, with $\mathrm{q}_{\mathrm{m}} 79.60 \mathrm{mg}$ $\mathrm{g}^{-1}$. Thermodynamic and kinetic investigations revealed that this process was favourable and endothermic in nature, following pseudosecond order kinetics.
\end{abstract}

Key Words: Citrullus lanatus peels, Alizarin Red-S, Adsorption, Isothermal modeling, Kinetics.

ᄂ - - - - - - - - - - - - - - - - - - - - - - - - - - - -

\section{INTRODUCTION}

Textile industries use a variety of dyeing materials for developing different colour shades. A massive amount of these dyes is wasted during processing which goes into effluents and poses problems for mankind and environmental abiotic and biotic factors by creating water pollution. Various kinds of synthetic dyes are commercially available. Among them, reactive anthraquinone dyes are extensively employed in textile industry due to their wide range of colour shades and ease of application. Their fused aromatic ring structures are the main cause of their inherent chemical stability and non-biodegradable nature ${ }^{1,2}$.

In this research project, Alizarin Red-S dye has been removed from water by adsorption. It is a common water soluble, anthraquinone textile dye and has been extensively employed since ancient times in sub-continental areas for cotton and silk dyeing. Its IUPAC name is 1,2-dihydroxy-9,10anthraquinonesulfonic acid sodium salt and structural formula is given in Fig. 1. Other common names of this dye are: Alizarin carmine and Mordant Red-3, diamond red-W and Alizarin red water soluble. It is orange powder having no odor. Persons having skin allergies are more susceptible to its hazardous effects. Its acute toxicity leads to irritation to skin, eyes, lungs, mucous membranes and gastro-intestinal tract. Whereas in chronic conditions it leads to dermatitis. It is synthesized from a natural dye alizarin, whose natural source is madder<smiles>O=C1c2ccccc2C(=O)c2c1cc(S(=O)(=O)[13OH])c(O)c2O</smiles>

Fig. 1. Structural formula of Alizarin Red-S dye

plant (Rubia tinctorum, L. rubiaceae), by sulfonation. This dye is also used in clinical practices for staining synovial fluid to assess for basic calcium phosphate crystals. In geology, it is used as a staining agent for identification of calcium carbonate minerals like calcite and aragonite ${ }^{3}$.

These dyes are not easily removed by routine wastewater treatment methodologies like chemical coagulation and precipitation, photo-catalytic degradation and chemical or biological oxidation due to their thermodynamic stability and resistance towards photo-catalytical or biological oxidizing agents ${ }^{4}$. The adsorption process in recent years provides an attractive substitutive method for waste water treatment, especially if the adsorbing material is low cost, indigenous, abundantly available and does not need a supplementary pre-treatment step before its application. Activated carbon, which is used normally, is expensive with inherent disadvantages like incomplete dye adsorption, high reagents and operating costs and toxic waste generation that involve safe dumping. Therefore, researchers are trying to find new alternative 
economical adsorbents from their indigenous sources like: apple pomace, wheat husk, rice husk, plant leaves, seeds, peels of fruits and vegetables, straw, corn cobs, barley husks etc. ${ }^{5-14}$. The adsorption of dye on agro-waste materials predominantly occurred by passive transport mechanisms because of the presence of variety of functional groups like amino, hydroxyl, carboxyl and phosphate etc.

In this research work Citrullus lanatus peels have been investigated as a sorbing material for the removal of Alizarin Red-S dye from water. Citrullus lanatus (common names: water melon or pepo, plant family: Cucurbitaceae) contains approximately $6 \%$ carbohydrates and $92 \%$ moisture by weight. It is an effective and cheap source of vitamin $\mathrm{C}$, citrulline, $\beta$-carotene and lycopene. More than 1200 varieties of it are used as a fruit in sub-continental areas, but as a vegetable in China, America and Africa ${ }^{15-20}$. Various operational parameters of adsorption were optimized. Then kinetic modeling along with adsorption isotherms had been investigated in the batch mode for predicting industrial applicability.

\section{EXPERIMENTAL}

Synthetic waste water preparation: Stock solution of Alizarin Red-S dye (empirical formula: $\mathrm{C}_{14} \mathrm{H}_{7} \mathrm{O}_{7} \mathrm{SNa}$, formula weight: $342.3 \mathrm{~g} \mathrm{~mol}^{-1}, \lambda_{\max }=423 \mathrm{~nm}$ ) from Sigma Aldrich was prepared by dissolving $1 \mathrm{~g} \mathrm{~L}^{-1}$ of de-ionized water. Further working solutions and standards were synthesized by dilutions of that solution as per requirement.

Preparation and functional groups characterization of Citrullus lanatus peels: Citrullus lanatus were purchased from local markets and washed. They were peeled off. Peels were chopped and dried in sun-light for a week. Then after complete drying in oven at $70{ }^{\circ} \mathrm{C}$ for $1 \mathrm{~h}$, they were ground and sieved through 50 ASTM mesh. After that, the fine powder was stored in plastic jars till further use. They were analyzed by recording their FT-IR spectrum in $4000-400 \mathrm{~cm}^{-1}$ range using Perkin Elmer Spectrum RX-I employing ATR cell ${ }^{21}$.

Adsorption studies: Batch scale study for optimizing adsorption parameters for removal of dye was done with $50 \mathrm{~mL}$ dye solution having $20 \mathrm{mg} \mathrm{L}^{-1}$ concentration $\left(\mathrm{C}_{\mathrm{o}}\right)$. The variables range studied were as followed: adsorbent dose (0.05-1.0 g), agitation time $(5-80 \mathrm{~min}), \mathrm{pH}(1-10)$, temperature $\left(20-70{ }^{\circ} \mathrm{C}\right)$ and concentration (5-40 ppm). After experiment, adsorbent was separated from sample solution by centrifugaion and remaining dye concentration $\left(\mathrm{C}_{\mathrm{e}}\right)$ in supernatant layer was determined spectrophotometrically at $423 \mathrm{~nm} \lambda_{\max }$. Optimized conditions were employed at the same time varying concentration of dye gradually for isothermal investigations, keeping other parameters constant. For kinetic studies, optimized parameters were employed by varying agitation time gradually, keeping others constant.

Desorption studies: For the regeneration of Citrullus lanatus peels sorption capacity after adsorptive removal of Alizarin Red-S dye, desorption experiments were carried out using various eluent solutions (i.e., $10 \mathrm{mmol} \mathrm{L}^{-1} \mathrm{NaOH}_{1} \mathrm{HNO}_{3}$ and $\mathrm{HCl}$ separately). For this purpose, $25 \mathrm{~g}$ of Citrullus lanatus peels, which were collected after adsorption experiments, were soaked in $100 \mathrm{~mL}$ of eluent solution separately for $20 \mathrm{~min}$, with continuous agitation at $150 \mathrm{rpm}$. After that concentration of Alizarin Red-S dye desorbed is determined spectrophotometrically and percentage desorption was calculated by comparing adsorbed quantity of Alizarin Red-S dye with desorbed quantity $^{21,22}$.

\section{RESULTS AND DISCUSSION}

Adsorbent surface characterization: The results of FT-IR spectral analysis of Citrullus lanatus peels are shown in Fig. 2. This spectral analysis revealed that Citrullus lanatus peels have different functional groups like: $-\mathrm{NH}$ and bounded $-\mathrm{OH}$ groups indicated by broad peak at $3400 \mathrm{~cm}^{-1},-\mathrm{CH}_{3}$ and $-\mathrm{CH}_{2}$ groups indicated their symmetric and asymmetric stretching vibrations bands at 2923 and $2851 \mathrm{~cm}^{-1}$ and their bending vibrations at 1378 and $1459 \mathrm{~cm}^{-1}$, respectively, $\mathrm{C}=\mathrm{O}$ of carboxylate group appeared at $1741 \mathrm{~cm}^{-1}, \mathrm{C}=\mathrm{O}$ of amide group is indicated by peak at $1652 \mathrm{~cm}^{-1},-\mathrm{SO}_{3}{ }^{2-}$ group is indicated by band at $1236 \mathrm{~cm}^{-1}$ and $\mathrm{P}=\mathrm{O}$ group is indicated by $1159 \mathrm{~cm}^{-1}$ bands ${ }^{18-21}$.

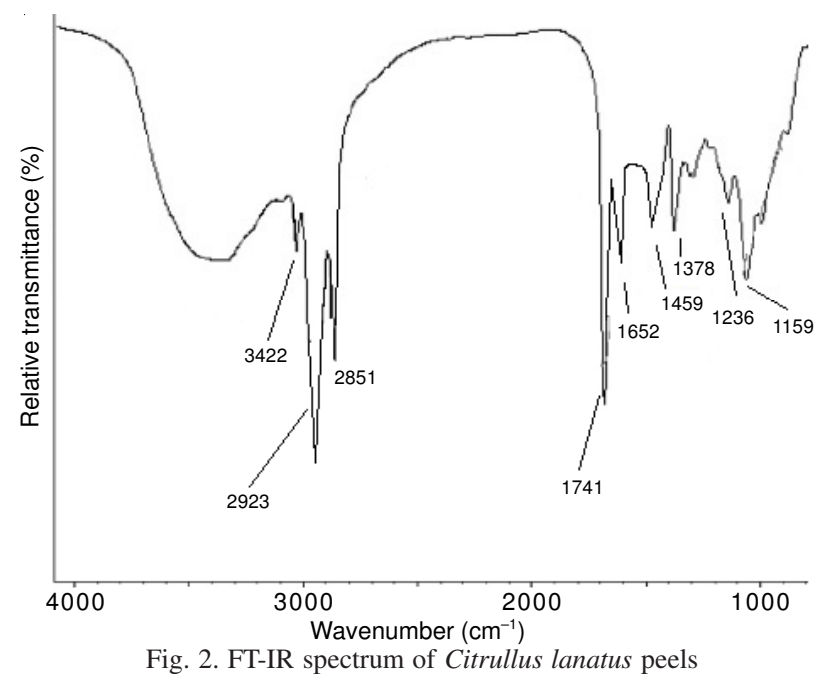

Operational parameters optimization: All the operational parameters were optimized step by step, keeping one factor variable at a time and others constant.

The effect of variation in adsorbent dose on sorptive removal of Alizarin Red-S dye was studied. The removal of dye was found to be maximum at $0.3 \mathrm{~g}$, i.e., $92.59 \%$ as shown in Fig. 3. Further increase in adsorbent dose has negative impact on sorption phenomenon, because of aggregation of adsorbent particles in solution. It results in blockage of available binding sites on Citrullus lanatus peels. So, optimized quantity of Citrullus lanatus peels was employed during isothermal and kinetic modeling experiments ${ }^{12,13}$.

For checking the effect of contact time between Citrullus lanatus peels and Alizarin Red-S dye solution on adsorption phenomenon, dye sample solutions were treated with $0.3 \mathrm{~g}$ adsorbent for various interval of time with constant agitation at $100 \mathrm{rpm}$ (Fig. 4). It is obvious from this figure that $89.44 \%$ of dye is removed within $40 \mathrm{~min}$. The increase in adsorption of dye with increasing time is due to the fact that Alizarin Red-S dye molecules generally forms mono-layer on Citrullus lanatus peels surface. Thus adsorption of dye from aqueous media is controlled by the transport rate of adsorbate species from outer to inner sites of adsorbing material ${ }^{14}$. 


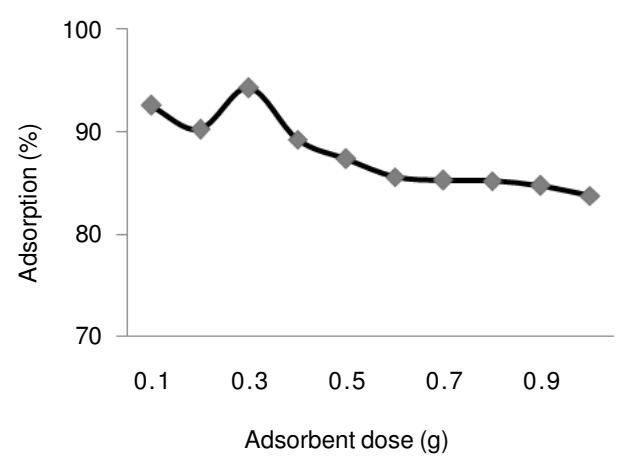

Fig. 3. Effect of adsorbent dose on the removal of Alizarin Red-S dye by Citrullus lanatus peels

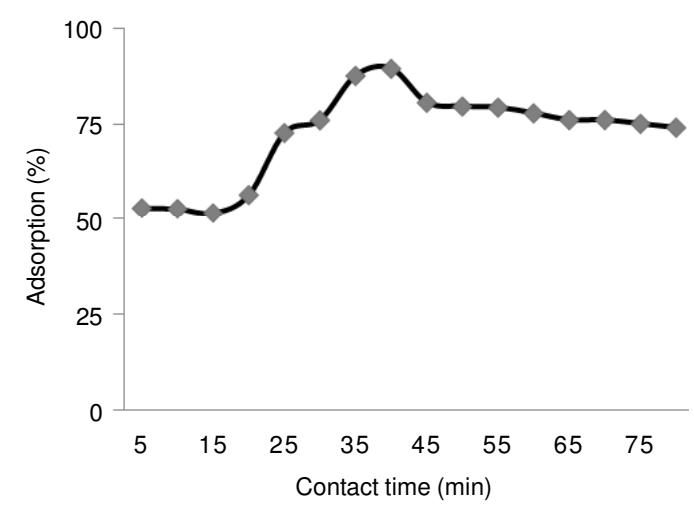

Fig. 4. Effect of agitation time on the removal of Alizarin Red-S dye by Citrullus lanatus peels

For studying effect of $\mathrm{pH}$ on adsorption of Alizarin RedS dye by Citrullus lanatus peels, the sample solutions of dye with $20 \mathrm{mg} \mathrm{L}^{-1}$ initial concentration were treated by $0.3 \mathrm{~g}$ adsorbent for $40 \mathrm{~min}$ with varying $\mathrm{pH} 1-10$. For maintain $\mathrm{pH}$ $0.01 \mathrm{M} \mathrm{HCl}$ and $0.01 \mathrm{M} \mathrm{NaOH}$ solutions were used. It is evident from Fig. 5, that when the aqueous solution of dye was treated with Citrullus lanatus peels, it was found that 95.74 $\%$ Alizarin Red-S dye removed at $\mathrm{pH} 2$ and $30.92 \%$ at $\mathrm{pH} 10$. Adsorption by agrowaste materials is greatly influenced by the $\mathrm{pH}$ of the solution. With the increase in $\mathrm{pH}$ beyond 4 , the adsorption declines sharply in this case. Therefore, the $\mathrm{pH}$ range of 2-4 is the optimum for this adsorption studies. Adsorption of a dye is dependent on the initial $\mathrm{pH}$ of the aqueous solution. At lower $\mathrm{pH}$, a negative network of charges is formed on the surface of bio-sorbing materials. Apart from this, acidic $\mathrm{pH}$ will affect the physiochemical process and hydrolysis of the dye $\mathrm{e}^{15}$.

The effect of concentration of Alizarin Red-S dye (5-50 $\mathrm{mg} \mathrm{L}^{-1}$ ) has been investigated with $0.3 \mathrm{~g}$ adsorbent dose and 40 min contact time. The removal of dye increased from 53.33 to $88.15 \%$. The results (Fig. 6) indicated that maximum adsorption of Alizarin Red-S dye on Citrullus lanatus peels is much dependent on the concentration of dye solution and occurred at $15 \mathrm{mg} \mathrm{L}^{-1}$. This might be due to the saturation of the accessible binding sites on the Citrullus lanatus peels due to greater competition for the fixed number of binding sites on biosorbent by more and more Alizarin Red-S dye species (ion-izable and non-ionizable), leading to a decline in the complexation of Alizarin Red-S dye by adsorbent.

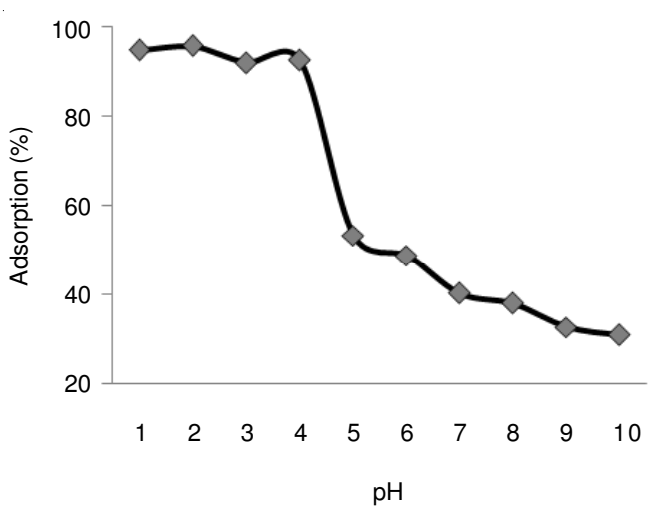

Fig. 5. Effect of $\mathrm{pH}$ on the removal of Alizarin Red-S dye by Citrullus lanatus peels

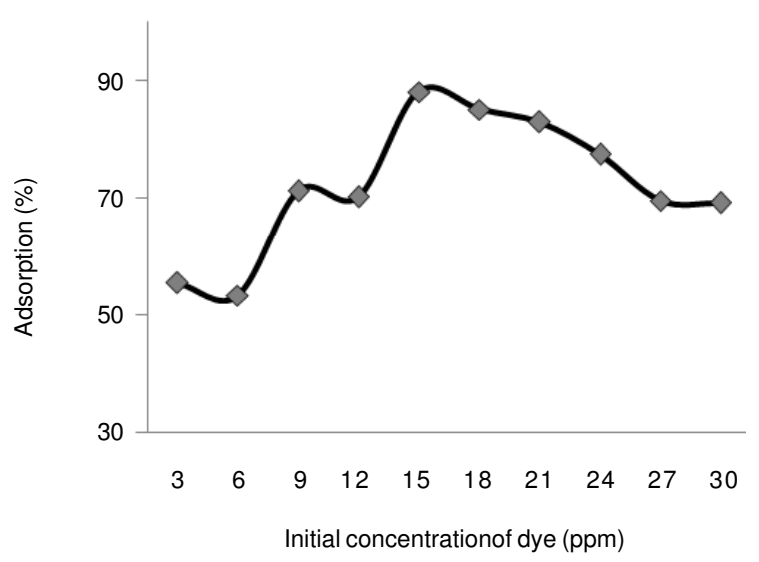

Fig. 6. Effect of adsorbate on the removal of Alizarin Red-S dye by Citrullus lanatus peels

Effect of temperature on adsorption of Alizarin Red-S dye by Citrullus lanatus peels was studied by varying it in the range of $20-80{ }^{\circ} \mathrm{C}$, using $0.3 \mathrm{~g}$ adsorbent dose and $15 \mathrm{~min}$ contact time. The results have been shown in Fig. 7. It was observed that the maximum removal of dye occurred at $40{ }^{\circ} \mathrm{C}$, i.e., $94.01 \%$. It is depicted from the graph that the removal of dye with increasing temperature would enhance the mobility of the Alizarin Red-S dye molecules and produces a bulging effect in biomass, thus facilitating the large molecules of dye to permeate further in Citrullus lanatus peels ${ }^{19-23}$. The temperature affects the removal rate of dye by enhancing the molecular interactions along with the solubility of dye $\mathrm{e}^{24}$.

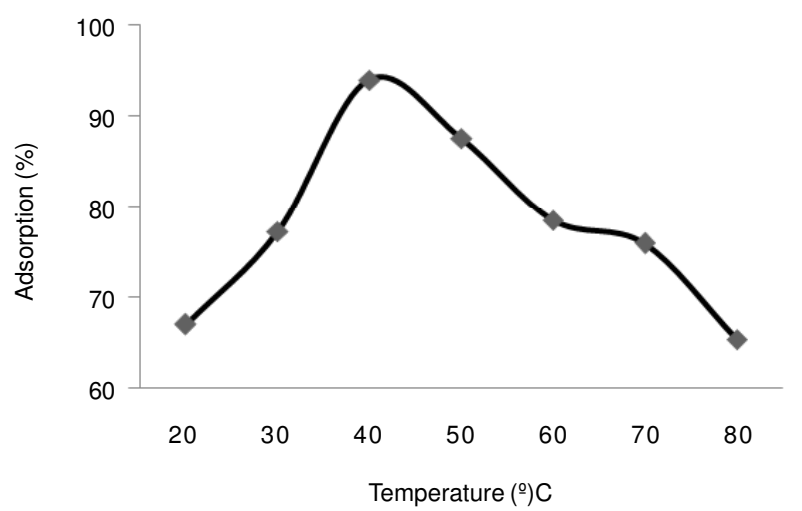

Fig. 7. Effect of temperature on the removal of Alizarin Red-S dye by Citrullus lanatus peels 
Kinetic modeling of equilibrium data: For evaluating controlling mechanism of adsorption of Alizarin Red-S dye by Citrullus lanatus peels, such as, mass transfer or chemical reaction, pseudo first and second order kinetic model is used to modulate the experimental data. Lagergren pseudo-first order rate equation:

$$
\log \left(\mathrm{q}_{\mathrm{e}}-\mathrm{q}_{\mathrm{t}}\right)=\log \mathrm{q}_{\mathrm{e}}-\left(\frac{\mathrm{k}_{1}}{2.303}\right) \mathrm{t}
$$

Here ' $\mathrm{k}_{1}$ ' is first order rate constant, ' $\mathrm{q}_{\mathrm{e}}$ ' is the dye amount in $\mathrm{mg} \mathrm{g}^{-1}$ adsorbed at equilibrium, ' $\mathrm{q}_{\mathrm{t}}$ ' is the dye amount in $\mathrm{mg}$ $\mathrm{g}^{-1}$ adsorbed at a specified time. Based on experimental results, linear plot of $\log \left(\mathrm{q}_{\mathrm{e}}-\mathrm{q}_{\mathrm{t}}\right)$ versus ' $\mathrm{t}$ ' is show in Fig. 8 for pseudo-first order kinetic modeling of equilibrium data. The kinetic data was further tested with Ho's pseudo-second order kinetics, which is given in eqn. 2 . It is based on the assumption that chemi-sorption involving valency forces through coordination or switch over of electrons linking adsorbent (Citrullus lanatus peels) and adsorbate (Alizarin Red-S dye) is the rate determining step ${ }^{24}$.

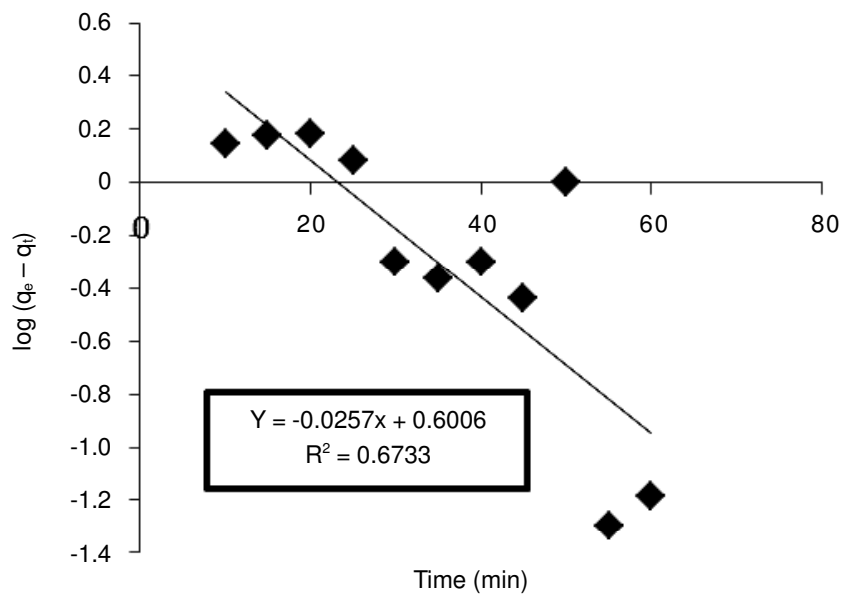

Fig. 8. Test of pseudo-first order equation for adsorption of Alizarin Red$\mathrm{S}$ dye by Citrullus lanatus peels

$$
\frac{\mathrm{t}}{\mathrm{q}_{\mathrm{t}}}=\frac{1}{\mathrm{k}_{2} \mathrm{q}_{\mathrm{e}}}+\frac{1}{\mathrm{q}_{\mathrm{e}} \mathrm{t}}
$$

Here ' $\mathrm{k}_{2}$ ' is the second order rate constant. Its respective graph of $\mathrm{t} / \mathrm{q}_{\mathrm{t}}$ versus $1 / \mathrm{t}$ is shown in Fig. 9 for pseudo-second order kinetic modeling of equilibrium data.

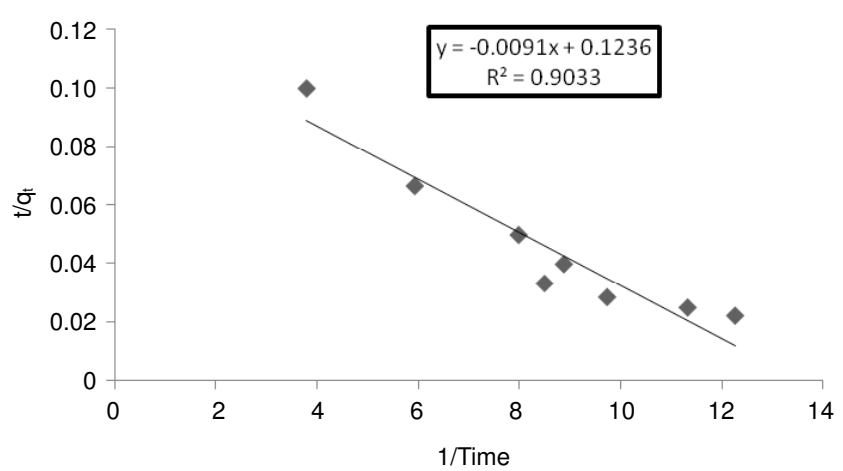

Fig. 9. Test of pseudo-second order equation for adsorption of Alizarin Red-S dye by Citrullus lanatus peels
It is clear from these graphs that pseudo-first order kinetic model is not applicable on the adsorption of Alizarin Red-S dye by Citrullus lanatus peels, because correlation coefficient $\mathrm{R}^{2}$ value is far from unity, i.e., 0.6733. It means that concentration of dye and adsorbent quantities, both matters in determining adsorption equilibrium. It is further confirmed by the applicability of pseudo-second order kinetic model with correlation coefficient $\mathrm{R}^{2}$ value close to unity, i.e., 0.9033 .

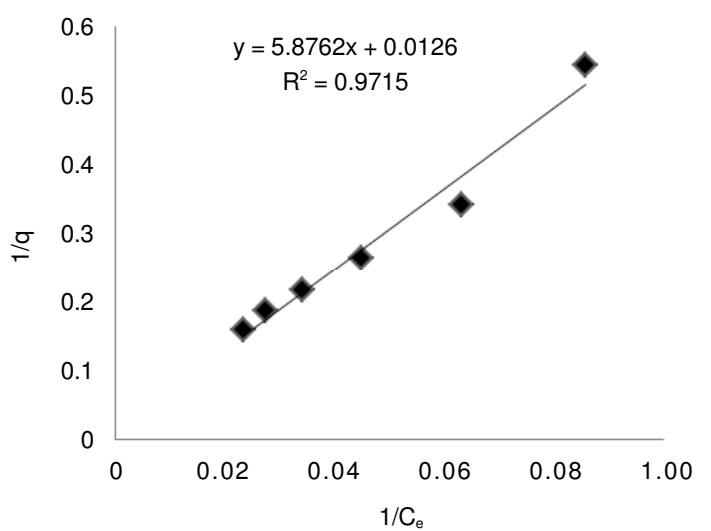

Fig. 10. Langmuir isotherm for adsorption of Alizarin Red-S dye by Citrullus lanatus peels

Isothermal modeling of equilibrium data: Dye distribution between the aqueous medium and adsorbent is a way to assess the equilibrium position in the adsorption process and generally articulated by Langmuir, Freundlich and Temkin isotherm models.

The equilibrium data obtained with varying concentration of adsorbate and fixed dose of adsorbent was applied to the Langmuir model as given below in eqn. 3:

$$
\frac{1}{\mathrm{q}}=\frac{1}{\mathrm{bq}_{\mathrm{m}} \mathrm{C}_{\mathrm{e}}}+\frac{1}{\mathrm{q}_{\mathrm{m}}}
$$

Here ' $\mathrm{q}$ ' is the amount of dye removed by adsorption, ' $\mathrm{q}_{\mathrm{m}}$ ' and ' $b$ ' $\left(\mathrm{L} \mathrm{g}^{-1}\right)$ are Langmuir constants. Their values are given in Table-1. Langmuir separation factor ' $\mathrm{R}_{\mathrm{L}}$ ' which is related to the affinity of binding sites, was calculated with eqn. 4 :

$$
\mathrm{R}_{\mathrm{L}}=\frac{1}{\left(1_{\mathrm{o}}+\mathrm{bC}_{\mathrm{o}}\right)}
$$

$R_{L}$ ranging from 0 to 1 indicates favourable adsorption. In this current experiment, ' $\mathrm{R}_{\mathrm{L}}$ ' is found to be 0.833 which indicates the irreversible nature of favourable adsorption. For calculating ' $\Delta \mathrm{G}^{\mathrm{o}}$ eqn. 5 was used:

$$
\Delta \mathrm{G}^{\mathrm{o}}=-\mathrm{RT} \ln \mathrm{K}
$$

Here $\Delta \mathrm{G}^{\mathrm{o}}$ came out as $-15.397 \mathrm{~kJ} \mathrm{~mol}^{-1}$, which is indicating the spontaneous nature of this process. In eqn. 5 , ' $\mathrm{R}$ ' is universal gas constant, ' $T$ ' is temperature in Kelvin and ' $\mathrm{K}$ ' is the reciprocal of Langmuir constant ' $b^{\prime 22,23}$. The basic assumptions of Langmuir model are: monolayer chemisorption occurs at specific homogeneous sites on adsorbing material and sorption capacity of the adsorbent is finite (Fig. 10).

The equilibrium data obtained with gradually varying concentration of Alizarin Red-S dye and $0.3 \mathrm{~g}$ adsorbent dose was applied to the Freundlich model given in eqn. 6 . Its basic 


\begin{tabular}{|c|c|c|c|c|c|c|}
\hline \multicolumn{7}{|c|}{$\begin{array}{l}\text { TABLE-1 } \\
\text { LANGMUIR AND THERMODYNAMICAL MODELING OF EQUILIBRIUM DATA FOR } \\
\text { ADSORPTION OF ALIZARIN RED-S DYE BY CITRULLUS LANATUS PEELS }\end{array}$} \\
\hline \multicolumn{5}{|c|}{ Langmuir Isotherm Parameters } & \multirow{2}{*}{$\begin{array}{l}\text { Separation factor } \\
\mathrm{R}_{\mathrm{L}}\end{array}$} & \multirow{2}{*}{$\begin{array}{l}\text { Thermodynamical parameters } \\
\qquad \Delta \mathrm{G}^{\circ}\left(\mathrm{kJ} \mathrm{mol}^{-1}\right)\end{array}$} \\
\hline Slope & Intercept & $\mathrm{R}^{2}$ & $\underset{\left(\mathrm{mg} \cdot \mathrm{g}^{-1}\right)}{\mathrm{q}_{\mathrm{m}}}$ & $\mathrm{b}\left(\mathrm{L} \mathrm{g}^{-1}\right)$ & & \\
\hline 5.876 & 0.013 & 0.971 & 79.60 & 0.002 & 0.833 & -15.397 \\
\hline
\end{tabular}

assumption is that non-uniform distribution of adsorbate on heterogeneous surface with physio-sorption.

$$
\log \mathrm{q}=\log \mathrm{K}_{\mathrm{F}}+\frac{1}{\mathrm{n}} \log \mathrm{C}_{\mathrm{e}}
$$

where ' $\mathrm{K}_{\mathrm{F}}$ ' $\left(\mathrm{mg}^{1-1 / \mathrm{n}} \mathrm{L}^{1 / \mathrm{n}} \mathrm{g}^{-1}\right)$ is adsorption capacity and ' $\mathrm{n}$ ' $(\mathrm{L} / \mathrm{mg})$ is adsorption intensity. They are Freundlich constants their values are obtained from regression analysis of graph plotted between $\log \mathrm{q}_{\mathrm{e}}$ versus $\log \mathrm{C}_{\mathrm{e}}$ (Fig. 11). The value of ' $\mathrm{n}$ ' in range of 0 to 1 (Table-2), figure out that the adsorption is compatible with the Freundlich isotherm model ${ }^{21}$.

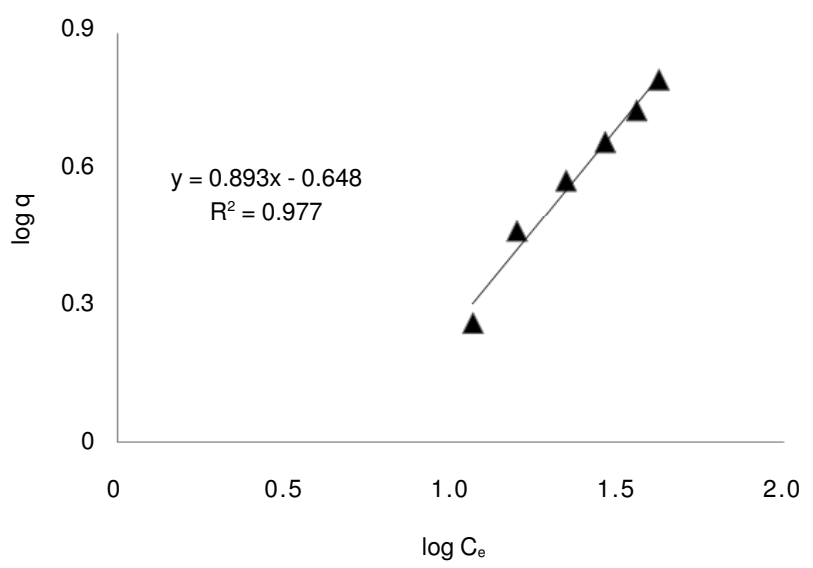

Fig. 11. Freundlich isotherm for adsorption of Alizarin Red-S dye by Citrullus lanatus peels

\begin{tabular}{ccccc}
\multicolumn{5}{c}{ TABLE-2 } \\
FREUNDLICH MODELING OF EQUILIBRIUM & \\
& DATA FOR ADSORPTION OF ALIZARIN RED-S & \\
\multicolumn{5}{c}{ DYE BY CITRULLUS LANATUS PEELS } \\
\hline Slope & Intercept & $\mathrm{R}^{2}$ & $\mathrm{~K}_{\mathrm{F}}\left(\mathrm{mg}^{1-1 / \mathrm{n}} \mathrm{L}^{1 / \mathrm{n}} \mathrm{g}^{-1}\right)$ & $\mathrm{n}$ \\
\hline 0.893 & -0.648 & 0.977 & 0.22 & 1.119 \\
\hline
\end{tabular}

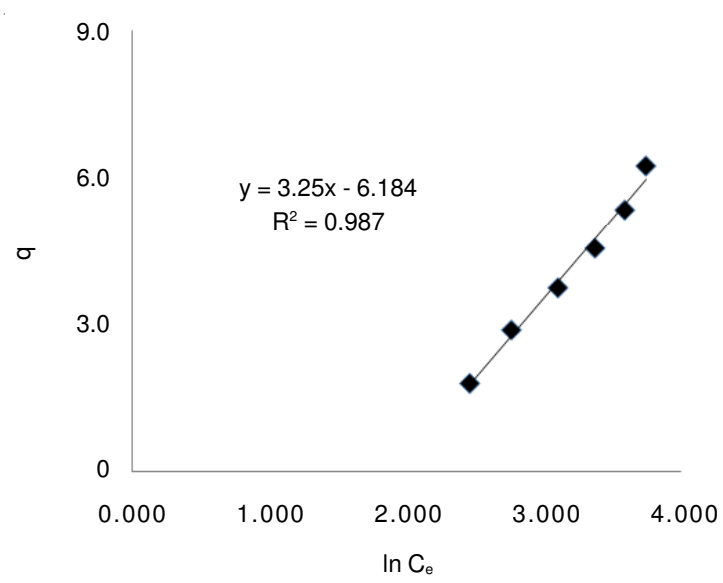

Fig. 12. Temkin isotherm for adsorption of Alizarin Red-S dye by Citrullus lanatus peels
Further equilibrium data is tested with Temkin isotherm model, which is given in eqn. 7 .

$$
\mathrm{q}=\mathrm{B}_{\mathrm{T}} \ln \mathrm{C}_{\mathrm{e}}+\mathrm{B}_{\mathrm{T}} \ln \mathrm{K}_{\mathrm{T}}
$$

Here ' $\mathrm{B}_{\mathrm{T}}$ ' $(\mathrm{kJ} / \mathrm{mol})$ and ' $\mathrm{K}_{\mathrm{T}}$ ' are Temkin isotherm constants. All the constants were determined by the regression analysis of linear plots of isotherm ${ }^{22-24}$. It is related with the effects of indirect adsorbate/adsorbent interactions on adsorption equilibrium and recommended that because of these physical interactions, heat of adsorption decrease linearly with adsorption of dye (Fig. 12).

The linear isothermal calculations and regression analysis depicted that equilibrium data agree well with the Temkin model $\left(R^{2}=0.987\right)$ as compared to Freundlich $\left(R^{2}=0.977\right)$ and Langmuir models $\left(\mathrm{R}^{2}=0.971\right)$. This behaviour suggested that the physiosorption occurr more as compared to chemisorption during removal of Alizarin Red-S dye by Citrullus lanatus peels. Heat of adsorption ' $\mathrm{B}_{\mathrm{T}}$ ' was $3.25 \mathrm{~kJ} / \mathrm{mol}$ for Alizarin Red-S dye. Its values less than 8 , which is the indication of physio-sorption (Table-3).

\begin{tabular}{ccccc}
\multicolumn{4}{c}{ TABLE-3 } \\
& TEMKIN MODELING OF EQUILIBRIUM \\
& DATA FOR ADSORPTION OF ALIZARIN \\
& RED-S DYE BY CITRULLUS LANATUS PEELS \\
\hline \multicolumn{5}{c}{ Temkin isotherm parameters } \\
\hline Slope & Intercept & $\mathrm{R}^{2}$ & $\mathrm{~K}_{\mathrm{T}}(\mathrm{L} / \mathrm{mg})$ & $\mathrm{B}_{\mathrm{T}}(\mathrm{kJ} / \mathrm{mol})$ \\
\hline 3.250 & -6.184 & 0.987 & 0.15 & 3.250 \\
\hline
\end{tabular}

Desorption studies: For regenerating Citrullus lanatus peels sorption capacity, various eluents were employed and results are given in Fig. 13. The desorption percentage of Alizarin Red-S dye from Citrullus lanatus peels with $\mathrm{NaOH}$, $\mathrm{HNO}_{3}$ and $\mathrm{HCl}$ was 94, 76 and $70 \%$, respectively. This indicated that dilute sodium hydroxide desorbs more Alizarin Red-S dye from Citrullus lanatus peels. It could be due to the anionic / acidic nature of dye, which is neutralized by basic environment, resulting in more desorption, as compared to acidic eluents ${ }^{23}$.

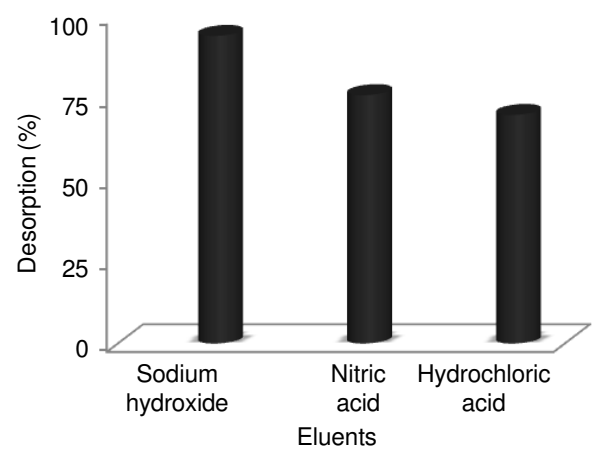

Fig. 13. Desorption of Alizarin Red-S dye from Citrullus lanatus peels using different eluents 


\section{Conclusion}

The results of the present adsorption study indicated that the maximum adsorption of Alizarin Red-S dye by Citrullus lanatus peels was obtained at $0.3 \mathrm{~g}$ adsorbent dose, $40 \mathrm{~min}$ agitation time, $\mathrm{pH} 2-4$, initial concentration of dye $15 \mathrm{mg} \mathrm{L}^{-1}$ and $40{ }^{\circ} \mathrm{C}$ temperature. The adsorption process mechanism was found as physio-sorption mode dominating over chemisorption mode of removal of dye, following pseudo-second order model and spontaneous nature (indicated from negative values of $\Delta \mathrm{G}^{\circ}$ ). Maximum adsorption capacity of Citrullus lanatus peels to remove Alizarin Red-S dye in optimized conditions is $79.60 \mathrm{mg} \mathrm{g}^{-1}$. Separation factor ' $\mathrm{R}_{\mathrm{L}}$ ' point outs the feasibility of this process, which is further confirmed by the linearity of equilibrium adsorption isothermal data correlation coefficient values. After adsorptive elimination of Alizarin Red-S dye by Citrullus lanatus peels, they can be easily regenerated by using sodium hydroxide in an economical way. The developed adsorption system is useful, low cost, efficient and environment friendly. It can be used for the removal of the Alizarin Red-S dye from contaminated water.

\section{REFERENCES}

1. Z. Belala, M. Jeguirim, M. Belhachemi, F. Addoun and G. Trouvé, Desalination, 271, 80 (2011).

2. T. Akar, I. Tosun, Z. Kaynak, E. Ozkara, O. Yeni, E.N. Sahin and S.T. Akar, J. Hazard. Mater., 166, 1217 (2009).
3. R. Rehman, T. Mahmud, J. Anwar, M. Salman, U. Shafique, W. Zaman and F. Ali, J. Chem. Soc. Pak., 33, 228 (2011).

4. J. Huang and K. Zhang, Desalination, 282, 19 (2011).

5. M.A.M. Salleh, D.K. Mahmoud, W.A.W.A. Karim and A. Idris, Desalination, 280, 1 (2011).

6. M.S. Tanyildizi, Chem. Eng. J., 168, 1234 (2011).

7. G. Moussavi and R. Khosravi, Chem. Eng. Res. Des., 89, 2182 (2011).

8. N.M. Mahmoodi and B. Hayati, M. Arami and C. Lan, Desalination, 268, 117 (2011).

9. R. Baccar, P. Blánquez, J. Bouzid, M. Feki and M. Sarrà, Chem. Eng. J., 165, 457 (2010).

10. R. Rehman, A. Abbas, A. Ayub, Qurat-ul-Ain, M. Salman, T. Mahmud, U. Shafique and W. Zaman, EJEAFChe, 10, 2531 (2011).

11. M.A. Ahmad and N.K. Rahman, Chem. Eng. J., 170, 154 (2011).

12. S.P. Sangal, Microchem. J., 9, 26 (1965).

13. M.J. Iqbal and M.N. Ashiq, J. Hazard. Mater., 139, 57 (2007).

14. A.M. Rimando and P. Perkins-Veazie, J. Chromatogr. A, 1078, 196 (2005).

15. M.O. Oluwamukomi, Afr. J. Food Sci., 3, 117 (2009).

16. M. Tarek, A.M. Magda, A.M. Saleh, S.M. Afaf and Fahmy, Bioresour. Technol., 68, 215 (1999).

17. M.B. Ibrahim and W.L.O. Jimoh, Indian J. Sci. Technol., 4, 487 (2011).

18. A. Addo and A. Bart-Plange, ARPN J. Agric. Biol. Sci., 4, 14 (2009).

19. S.T. Akar, S. Arslan, T. Alp, D. Arslan and T. Akar, Chem. Eng. J., 185186, 82 (2012).

20. N.A. Aviara and O.O. Ajibola, J. Food Eng., 55, 107 (2002).

21. C. Djilani, R. Zaghdoudi, A. Modarressi, M. Rogalski, F. Djazi and A. Lallam, Chem. Eng. J., 189-190, 203 (2012).

22. R. Rehman, J. Anwar and T. Mahmud, J. Chem. Soc. Pak., 34, 460 (2012).

23. R. Sowmeyan, J. Santhosh and R. Latha, Int. Res. J. Biochem. Bioinform., 1, 297 (2011).

24. Y.S. Ho and G. McKay, Process Biochem., 76, 451 (1999). 